\title{
First example of a conducting polymer synthesised in supercritical fluids
}

\author{
Francesca M. Kerton, Gerard A. Lawless and Steven P. Armes* \\ School of Chemistry, Physics and Environmental Science, University of Sussex, Falmer, Brighton, UK BN19QJ
}

Polypyrrole is synthesised via thermal decarboxylation of a precursor monomer, pyrrole-2-carboxylic acid, using ferric salts in both supercritical carbon dioxide and supercritical fluoroform; pressed pellet conductivities were as high as $2 \times 10^{-2} \mathrm{~S} \mathrm{~cm}^{-1}$ and scanning electron microscopy studies revealed an unusual non-spherical morphology.

There is increasing interest in carrying out chemical reactions and extractions in environmentally benign solvents such as supercritical carbon dioxide $\left(\mathrm{scCO}_{2}\right)$. This approach has several potential advantages, including low solvent cost and toxicity, ease of solvent removal, potential for recycling and variation of reaction rates by relatively small changes in pressure. ${ }^{1}$ Recently DeSimone and co-workers published a series of papers describing the synthesis of polystyrene, poly(methyl methacrylate), poly(acrylic acid) and perfluorinated polymers via dispersion, precipitation and solution polymerisation in $\mathrm{ScCO}_{2}{ }^{2-5}$

Polypyrrole is a relatively air-stable organic conducting polymer which is easily prepared as an insoluble black powder by chemical oxidative polymerisation in water, ethyl acetate, acetonitrile, methanol or diethyl ether. ${ }^{6}$ In this work we describe the synthesis of polypyrrole in both $\mathrm{scCO}_{2}$ and supercritical fluoroform $\left(\mathrm{scCHF}_{3}\right)$. The precursor monomer route $^{7}$ described by workers at DSM Research was selected. This approach allowed good control over the onset of the polymerisation since the in situ generation of pyrrole monomer by decarboxylation only occurs at elevated temperature (see Scheme 1). As far as we are aware, this is the first example of the synthesis of a conducting polymer in supercritical fluids.

Polymerisations were conducted either in a $300 \mathrm{ml}$ Paar pressure vessel fitted with a mechanical stirrer or else a $10 \mathrm{~mm}$ sapphire NMR tube as described earlier. ${ }^{8}$ The reaction vessel was charged with the desired amounts of precursor monomer ( 0.3 to $1.0 \mathrm{~g}$ ) and oxidant (either $\mathrm{FeCl}_{3}$ or $\mathrm{Fe}\left(\mathrm{CF}_{3} \mathrm{SO}_{3}\right)_{3}$; the initial molar oxidant/monomer ratio was fixed at 2.33 in each case) prior to pressurising with $\mathrm{CO}_{2}$ or $\mathrm{CHF}_{3}$. The vessel was heated to $80-110^{\circ} \mathrm{C}$; under these conditions a supercritical continuous phase was achieved (i.e. the pressure exceeded 72 bar for $\mathrm{CO}_{2}$ and 46.9 bar for $\mathrm{CHF}_{3}$; see Table 1) and the rate of thermal decarboxylation of the pyrrole-2-carboxylic acid was rapid. After $2-3 \mathrm{~h}$ the polymerisation was terminated by cooling the vessel to room temperature and slowly venting the gaseous $\mathrm{CO}_{2}$ or $\mathrm{CHF}_{3}$.

Preliminary NMR studies indicated that both the pyrrole2-carboxylic acid precursor monomer and the $\mathrm{FeCl}_{3}$ oxidant have relatively limited solubility in $\mathrm{scCO}_{2}$. However, both pyrrole monomer and the $\mathrm{Fe}\left(\mathrm{CF}_{3} \mathrm{SO}_{3}\right)_{3}$ oxidant were soluble in this medium, as judged by visual inspection of these reagents in sapphire NMR tubes (in the case of pyrrole, a good quality proton NMR spectrum was readily obtained in $\mathrm{scCO}_{2}$ ). The $\mathrm{FeCl}_{3}$ oxidant proved to be more soluble in $\mathrm{scCHF}_{3}$. These observations are consistent with the higher level of residues found in polypyrroles prepared with $\mathrm{FeCl}_{3}$ oxidant in $\mathrm{scCO}_{2}$ (see Table 1).

Prior to our experiments we were sceptical about the efficiency of thermal decarboxylation (loss of $\mathrm{CO}_{2}$ ) of the pyrrole-2-carboxylic acid precursor in the presence of $\mathrm{scCO}_{2}$. However, reasonable yields $(50-60 \%$ based on monomer) of polypyrrole were obtained within 2 to $3 \mathrm{~h}$ with $\mathrm{FeCl}_{3}$ (see Table 1). A near-quantitative yield of polypyrrole was obtained using the more soluble $\mathrm{Fe}\left(\mathrm{CF}_{3} \mathrm{SO}_{3}\right)_{3}$ oxidant. FT-IR spectra of the $\mathrm{scCO}_{2}$-synthesised polypyrroles were very similar to that of conventional polypyrrole ${ }^{9}$ prepared in water at room temperature. Bulk powder densities were in the range $1.55-1.65 \mathrm{~g} \mathrm{~cm}^{-3}$ as measured by helium pycnometry, which

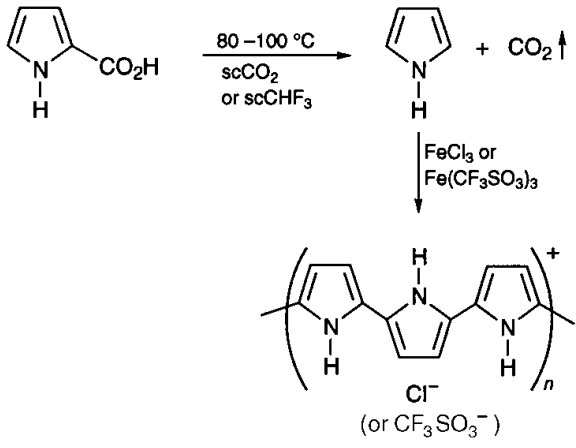

Scheme 1

Table 1 Effect of synthesis parameters on the yield, conductivity, residues content and doping level of polypyrroles prepared in supercritical media

\begin{tabular}{|c|c|c|c|c|c|c|c|c|}
\hline entry & oxidant & solvent & $T /{ }^{\circ} \mathrm{C}$ & pressure/bar & yield $^{a}(\%)$ & doping level $^{b}$ & conductivity ${ }^{c} / \mathrm{S} \mathrm{cm}^{-1}$ & residues $^{d}(\%)$ \\
\hline 1 & $\mathrm{FeCl}_{3}$ & toluene & 110 & 1 & 92 & 0.16 & $9 \times 10^{-4}$ & 1.5 \\
\hline 2 & $\mathrm{FeCl}_{3}$ & $\mathrm{scCO}_{2}$ & 110 & 72 & 54 & 0.25 & $3 \times 10^{-3}$ & 13.6 \\
\hline 3 & $\mathrm{FeCl}_{3}$ & $\mathrm{scCO}_{2}$ & 80 & 150 & 63 & 0.24 & $5 \times 10^{-2}$ & 7.6 \\
\hline 4 & $\mathrm{Fe}\left(\mathrm{CF}_{3} \mathrm{SO}_{3}\right)_{3}$ & $\mathrm{scCO}_{2}$ & 80 & 150 & 87 & 0.21 & $2 \times 10^{-2}$ & 0.8 \\
\hline 5 & $\mathrm{FeCl}_{3}$ & $\mathrm{scCHF}_{3}$ & 90 & 48 & 57 & 0.20 & $1 \times 10^{-3}$ & 0.0 \\
\hline
\end{tabular}

${ }^{a}$ Calculated based on pyrrole monomer, assuming complete thermal decarboxylation of the pyrrole-2-carboxylic acid precursor. ${ }^{b} \mathrm{Calculated}$ from elemental microanalyses $\left(\mathrm{Cl} / \mathrm{N}\right.$ or $\mathrm{S} / \mathrm{N}$ ratios). ${ }^{c} \mathrm{As}$ measured on pressed pellets at room temperature using the four-point probe method. ${ }^{\mathrm{d}} \mathrm{As}$ determined from thermogravimetric analyses (scan rate: $20^{\circ} \mathrm{C}$ per min in air). 
are in reasonable agreement with literature values. ${ }^{9}$ Pressed pellet conductivities (four-point probe technique) were as high as $5 \times 10^{-2} \mathrm{~S} \mathrm{~cm}^{-1}$ for the polypyrrole prepared using the $\mathrm{Fe}\left(\mathrm{CF}_{3} \mathrm{SO}_{3}\right)_{3}$ oxidant. This value is two to three orders of magnitude lower than those of polypyrrole prepared in conventional solvents ${ }^{6,9}$ and probably reflects some over-oxidation of the conjugated chains. Indeed, a weak carbonyl feature at ca. $1700 \mathrm{~cm}^{-1}$ was observed in the IR spectra of these materials which is normally absent in the IR spectrum of polypyrrole synthesised using $\mathrm{FeCl}_{3}$ in conventional solvents. ${ }^{9}$ This is understandable given the elevated temperature required for this precursor route. Indeed, an even lower conductivity $\left(9 \times 10^{-4} \mathrm{~S} \mathrm{~cm}^{-1}\right)$ was obtained for a 'control' polypyrrole synthesised in refluxing toluene (see entry 1 in Table 1 ). The $\mathrm{Cl} / \mathrm{N}$ (or $\mathrm{S} / \mathrm{N}$ ) ratios calculated from elemental microanalyses indicate doping levels of 0.20 to 0.25 , which are slightly lower than the normally accepted doping range of $0.25-0.33$ for polypyrrole. $^{6}$

Thermogravimetric analyses indicated significant levels of incombustible residues ( 7.6 to $13.6 \%$ at $c a .600{ }^{\circ} \mathrm{C}$ ) in polypyrroles synthesised using $\mathrm{FeCl}_{3}$ in $\mathrm{scCO}_{2}$, even after extensive washing of the precipitated polymer with methanol and water. This is most likely due to polypyrrole deposition onto insoluble $\mathrm{FeCl}_{3}$ particulates. On the other hand, negligible residues $(<1 \%)$ were obtained for polypyrroles prepared using $\mathrm{Fe}\left(\mathrm{CF}_{3} \mathrm{SO}_{3}\right)_{3}$ in $\mathrm{scCO}_{2}$ and $\mathrm{FeCl}_{3}$ in $\mathrm{scCHF}_{3}$, which suggests that these more soluble oxidants are easily removed during clean-up.

Polypyrroles prepared via conventional precipitation polymerisation in aqueous or non-aqueous media invariably exhibit globular morphologies comprising pseudo-spherical features of sub-micrometre dimensions. ${ }^{9}$ A typical scanning electron micrograph is shown in Fig. 1(a). In contrast, scanning electron microscopy studies of the $\mathrm{scCO}_{2}$-synthesised polypyrroles (entries 3-5 in Table 1) revealed an unusual fibrillar morphology [see Fig. 1(b)]. The material is made up exclusively of thin fibres or strands, several micrometres in length and approximately 100 to $200 \mathrm{~nm}$ in diameter. Similar morphologies were reported by DeSimone's group for poly(acrylic acid) prepared in $\mathrm{scCO}_{2} \cdot{ }^{3}$ The relatively low viscosity of the supercritical fluid may be a significant factor in producing this polypyrrole morphology. However, BET measurements confirmed that the specific surface areas of these fibrillar polypyrroles were comparable to those reported by Maeda and Armes for conventional globular polypyrrole. ${ }^{10}$

In summary, polypyrrole has been synthesised in supercritical fluids for the first time. Yields were moderate to high, depending on the reaction conditions. The spectroscopic and physicochemical properties of these materials were generally very similar to those of polypyrrole prepared in conventional solvents. However, pressed pellet conductivities were somewhat lower and unusual non-spherical morphologies were obtained. Clearly further investigations of the synthesis-structure-property relationships of these materials are warranted.

F. M. K. thanks the EPSRC for a DPhil studentship. S. P. A. thanks the EPSRC for capital equipment grants for the BET and helium pycnometer instruments (GR/K01841). The DRA and DSM Research are thanked for partially funding the purchase of the FT-IR spectrometer.

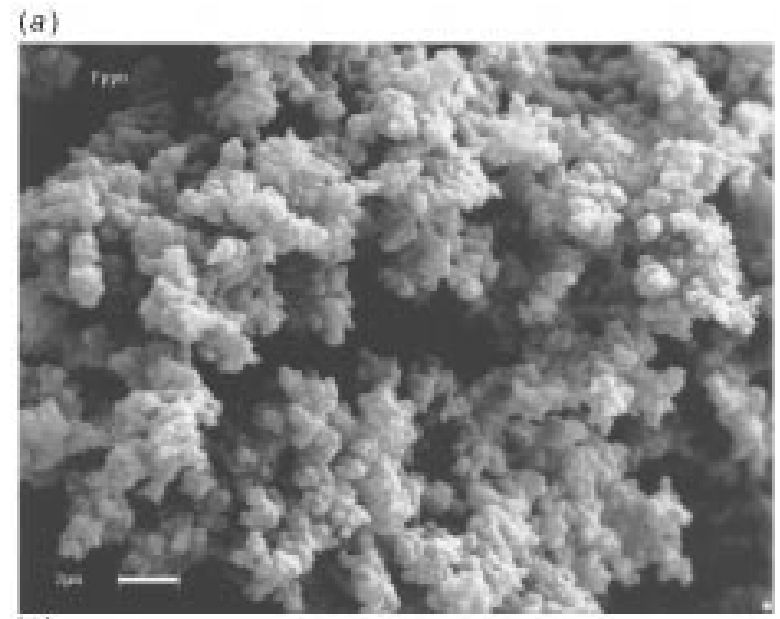

(b)

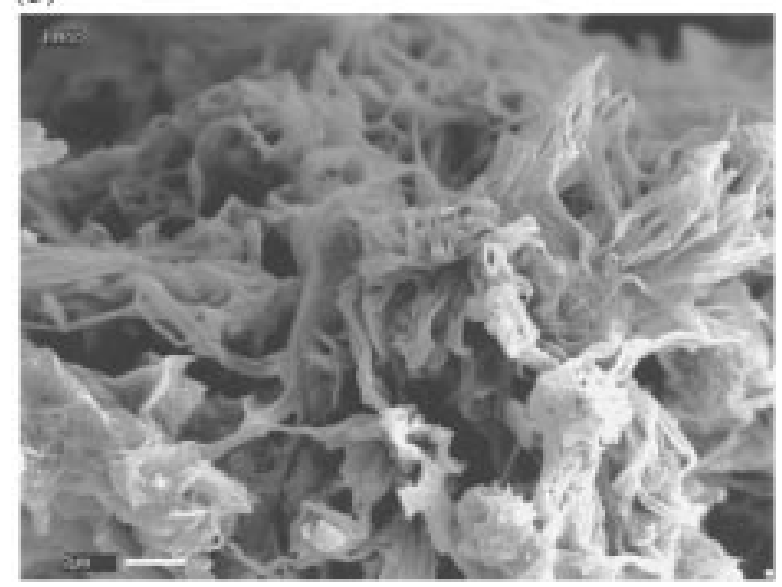

Fig. 1 Scanning electron micrographs of polypyrroles prepared using $\mathrm{FeCl}_{3}$ in $(a)$ water at $25^{\circ} \mathrm{C}$ and $(b) \mathrm{scCO}_{2}$ at $80^{\circ} \mathrm{C}$ (entry 3 in Table 1 )

\section{References}

1 M. A. McHugh and V. J. Krukonis, Supercritical Fluid Extraction: Principle and Practice, Butterworths, Stoneham, MA, USA, 2nd edn., 1994.

2 D. A. Canelas, D. E. Betts and J. M. DeSimone, Macromolecules 1996, 29, 2818.

3 J. M. DeSimone, E. E. Maury, Y. Z. Menceloglu, J. B. McClain, T. J. Romack and J. R. Combes, Science, 1994, 265, 356.

4 T. J. Romack, E. E. Maury and J. M. DeSimone, Macromolecules, 1995, 28, 912 .

5 J. M. DeSimone, Z. Guan and C. S. Elsbernd, Science, 1992, 257, 945.

6 R. E. Myers, J. Electron. Mater., 1986, 2, 61.

7 H. van Dijk, O. Aagaard and R. Schellekens, Synth. Met., 1993, 55-57, 1085.

8 I. T. Horvath and E. C. Ponce, Rev. Sci. Instrum., 1991, 62, 1104

9 S. Maeda and S. P. Armes, J. Mater. Chem., 1994, 4, 935.

10 S. Maeda and S. P. Armes, Synth. Met., 1995, 73, 151.

Communication 7/04479H; Received 25th June, 1997 